\title{
SEMANTIC ACQUISITION IN LANGUAGE IMPAIRED AND NORMAL SPEAKING FOUR YEAR OLD CHILDREN
}

\author{
MARLENE GREEN B.A. (SP. \& H. THERAPY) (WITWATERSRAND)
}

\section{SUMMARY}

For the purpose of assessing a semantic feature theory of semantic acquisition in language impaired and normal pre-schoolers, semantic feature manipulation tests were administered to two language-impaired and two matched normal speaking four-year olds. Results support Clark's hypothesis that lexical acquisition proceeds from over-extended quasi-superordinate terms with few semantic features to more differentiated subordinate terms with a greater number of features. Language impaired and normal children did not seem to be differentiated on these results.

\section{OPSOMMING}

Die volgorde van die aanleer van semantiese eienskappe is by taalgestremde en normale voorskoolse kinders nagegaan. 'n Toets vir die manipulering van semantiese eienskappe is op twee taalgestremde en twee a fgepaarde normale 4 jaar oue kinders toegepas. Die resultate bevestig Clark se hipot ese dat leksika le aanleer geskied vanaf 'n baie breë algemene term met 'n paar semantiese eienskappe na 'n fyner gedifferensieerde onderverdeling van terme met 'n groter aantal kenmerke. Daar is nie 'n verskil gevind tussen normale kinders en kinders met taalprobleme nie.

Up to the present time research in linguistic development has concentrated mainly on syntactic growth. ${ }^{6,10,16,17}$ Little emphasis has been placed on the acquisition of semantics (which is the system of meaning underlying language in the deep structure) although this system is gaining recognition as an important part of native-speaker competence. ${ }^{3,4,14,17}$ While semantic acquistion plays an essential role in language growth, it also seems important in cognitive structure and growth. As Bierwisch ${ }^{3}$ postulates, semantic universals might indeed form the basis for human perceptual and cognitive development.

In semant ic theory it is generally accepted that the units of meaning are lexical items. These are verbal concepts and comprise combinations of semantic markers which represent features abstracted from reality. ${ }^{3,10,14}$ For example, "dog" is a lexical item comprising the features $<+$ animate $><-$ human $><+4$ legs $><+$ canine $>$ etc.

Having defined lexical items as verbal concepts, it is necessary to examine the notion of concepts. From the literature the following four main generalizations can be drawn: $5,7,8,9,11,12,19,20,23,26$ 
1. Concepts are the symbolic means whereby events which are discriminably different are rendered equivalent, due to their common incorporation of critical features, in order to form a class or category. The exemplars or members of the class formed in this way become differentiated from all other objects or events due to the presence (versus the absence) of the relevant critical features. Therefore, "bananas", "meat" and "milk" which all contain the feature <+ edible> are classed together as exemplifying "food" in contrast to "paint" and "hat", which exclude this feature.

2. The extraction or isolation of features from a stimulus configuration, usually for the purposes of forming a concept, is termed abstraction. When abstracted features are used as the criteria of a category, generalization is said to occur.

3. The greater the number of criterial features, the more specific or concrete is the defined class. Therefore, where there is a single criterial feature the defined class is broader and more abstract than any subordinate class (lexical item) with more features and hence greater definition. The class defined with a single criterial feature thus includes more exemplars. Therefore, the concept "food", which has only the feature $\langle+$ edible $\rangle$, is a broad superordinate concept. In contrast "fruit" also includes the features $<+$ tree-grown $><+$ natural $>$ and lies subordinate to "food", although "fruit" in turn is broader than, and superordinate to "apple" which includes extra features ( $<+$ edible $><+$ fruit $><+$ apple $t r e e>$ etc.)

4. Concepts, because they focus on critical features, and ignore those which are irrelevant, are economic in terms of storage and retrieval in an efficient model of cognition.

Thus, in verbal concepts, the features which have been abstracted are termed semantic markers or features. It is the method whereby these are abstracted and generalized which concerns us in the study of semantic acquisition.

Until recently no satisfactory theory had been proposed on semantic acquisition. Eve V. Clark ${ }^{10}$, has however, attempted to integrate diarized observations and experimental evidence on word-meaning acquisition in young children into a conceptually feasible theory of semantic development. Clark ${ }^{10}$ emphasizes that the number of extracted features determine the breadth of the defined category. She hypothesizes that verbal classes are first defined in early language acquisition by the presence of one semantic feature - these pseudo superordinate classes are thus broad and poorly differentiated, and termed "overextended" by Clark. ${ }^{10}$ With the addition of differentiating criterial semantic features during the development of the semantic system, the classes achieve greater definition and better symbolize reality. Only when all differentiating features are incorporated into the meaning of the lexical entry, can further feature abstraction be achieved. At this later stage, when common features within a category can be abstracted, true superordinate concepts will develop. These true superordinates will have the fewest semantic features. Thus the direction of semantic growth as hypothesized by Clark, ${ }^{10}$ is vertical, from the overextended pseudo-superordinate (and often fictitious) class, downwards to the concrete, where the class is clearly defined by a great number of features abstracted from the environment. It is only when all the 
features are present in the lexicon of the concrete items that it is possible for the child to abstract what features are common to the items, and he is able to construct the valid vertical semantic hierarchy with correct and highly abstract superordinates, and progressively more concrete subord inates. stract superordinates, and progressively more concrete subordinates.

In this way, Clark ${ }^{10}$ has clarified the central controversy of semantic acquisition theory, namely the direction of growth in semantic development. 1,16,26 In addition her theory allows understanding of difference between adult and child word-meaning. These differences are thus seen as qualitative.

Further her theory lies in close agreement with Vygotsky, ${ }^{26}$ as both emphasize that the strategy used for abstracting semantic features from the environment closely affects the meaning of the word thus evolved.

In accounting for this, Vygotsky ${ }^{26}$ postulates three phases in the acquisition of word-meaning:

1. Syncretism: Heaps of objects with arbitrary and unstable relationships are categorized together, and the words labelling these reflect the nature of the categorization.

2. Complexes: Concrete abstractions are made from the environment, often reflecting functional similarities. The words used reflect the concrete nature of the abstractions, though referring to the same referents as the adult words. This allows communication between adult and child. This strategy occurs in adults too; to some degree.

3. Conceptual thought occurs when the child is no longer bound by concrete interrelationships. Word meanings symbolize only the abstracted features as in adult thought.

Therefore, early in semantic development, words represent classes formed according to synthetic or complexive strategies. $\Lambda$ this stage, the labels of focal items can be projected onto items associated with them perceptually. For example, "bow-wow", though originally representative of "dog" and "toy-dog", becomes attached to "buttons", "cufflinks" and small long objects. The features abstracted from the original, i.e. oblong shape or shiny surface, have caused generalization of the original label (Vygotsky p. 70). Later in development abstraction strategies approximate those used by adults, and the resultant word meanings approximate those of adult thought. Thus, as the strategy affects word-meaning, it seems important to determine what strategies of abstraction the child used for attaching meaning to words. Another dimension of cognitive mechanisms in semantic growth is emphasized by Bloom ${ }^{4}$. She feels that language learning is semantically based. Her con- 1 tention is that syntactic relationships and the existence of the form-classes (e.g. noun, verb, adjective) result form the child's observations that certain words and their referents constantly appear in fixed relationships. The abstraction of these fixed relationships, allows words of the same form-class to be used interchangeably. Language acquisition is achieved by the child correlating his experiential observations of relationship between agent, action and object, with the adult verbal input symbolizing these relationships. For example "The boy pats the dog" and "The girl eats the cake" symbolize the same 
relationship (agent, action, object), and adult verbal input confirms this relationship.

If, as Bloom ${ }^{4}$ suggests, language learning is semantically based, then, in the field of speech pathology, it is necessary to assess this aspect in children who have not learned language correctly. Diagnosis for the individual child seems important, as areas of breakdown of linguistic learning seem to be individualized $^{2}, 21$. Perhaps then for some language impaired child ren there is difficulty in abstracting relationships from the environment.

The literature further suggests the presence of cognitive deficiency in children who learn language in a deviant manner. However, this deficiency has been inadequately defined ${ }^{21}$ and requires further attention.

From the preceding discussion it can be seen that there is a need for research into semantic theory and cognition for the following reasons:

1. A semantic feature acquisition hypothesis is as yet tentative and requires substantiation.

2. It is necessary to understand conceptual strategies of abstracting features from the environment as these seem to affect word-meaning acquisition.

3. As children with language impairment seem to have conceptual disorders, it is necessary to investigate whether this occurs in the area of abstracting meaning from the environment.

\section{METHOD}

AIMS

In view of the preceding rationale, the present study had as its aim the following:

1. To devise an adequate semantic test based on semantic feature abstraction and generalization in order to:

(a) assess the reality of the feature acquisition theory of semantics and to

(b) assess whether language impaired and normal children can be differentiated on this level.

2. To investigate cognitive strategies used in the abstraction of meaning in order to ascertain whether these differentiate language impaired and normal children.

3. To ascertain whether verbal concepts actively emphasized in the child's' environment are acquired in a manner different from those used less consciously or actively. Further, it aimed to see whether differential experience with the words caused differences between the language impaired and normal children.

\section{SUBJECTS:}

Two four year old boys with language impairment and two normal matched controls were used for the purpose of this study. In order to ensure maximum homegeneity within the sample for purposes of valid comparison, all subjects 
were selected according to the following criteria:

1. All subjects were four years old, as at this stage the language of children with normally developing language is contrasted markedly with that of children with language impairment. This dffferentiation is apparent because normal four-year-olds have correctly developed complex syntax and several transformations while language impaired children have developed few or deviant rules. Diagnosis of language impairment is thus fairly certain at this age.

While investigations into vocabulary development have utilized either very young children, ${ }^{10}$ or children older than six years, ${ }^{1,16}$ none have attended to the age group between those - the four-year-olds.

Another factor motivating choice of four-year-olds is that rate of vocab. ulary acquisition is reported to peak at about four years, thereafter prog. ressively decreasing with age. ${ }^{17}$

2. Male subjects were selected to control for certain differences in language acquisition found between males and females. Males, as a group, seem to acquire language later and more slowly than females, during the first few years. ${ }^{13}$

3. All subjects had older siblings. This was controlled for, as first-born children are reported to acquire language at a greater rate than their siblings. 18

4. Further all children were judged subjectively by the experimenter and the subjects' nursery school teachers to be of normal intelligence and to have no behavioural problems. These criteria were used in an attempt to control for factors other than linguistic ability which might influence performance on verbal, perceptual or conceptual tasks. ${ }^{25}$

Experimental Subjects ( $\mathrm{LI}_{1}$ and $\mathrm{LI}_{2}$ ): The essential criteria for selection of the experimental subjects were that they had been previously diagnosed as language impaired, and that they were presently attending speech therapy. Experienced language pathologists at the University of the Witwatersrand's Speech and Hearing Clinic diagnosed the errors in the subjects' language as reflecting a deviation rather than a delay in linguistic acquisition. Maturation would thus not remedy the errors, as would occur with language delay. ${ }^{18}$ Control Subjects $\left(\mathrm{N}_{1}\right.$ and $\left.\mathrm{N}_{2}\right)$ : Each language impaired subject was matched with a male control subject from the same nursery school, who was closest in age to him. and who was regarded by the teacher to have normal language and intelligence.

The linguistic ablity of all subjects was assessed in terms of its deviation or sophistication and an attempt was made to rank the linguistic ability of the subjects in relation to each other by the experimenter and an experienced language pathologist. $\mathrm{LI}_{1}$ was judged to have a greater degree of impairment than $\mathbf{L I}_{2}$, while $\mathrm{N}_{1}$ was assessed as having less mature language than $\mathrm{N}_{2}$.

Table 1 summarises all variables where differences were found between the subjects. It is concerned with age, sibling position and linguistic ranking and description. 


\begin{tabular}{|c|c|c|c|c|c|}
\hline 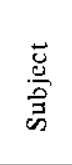 & $\stackrel{M}{*}$ & 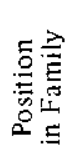 & 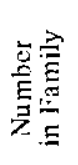 & 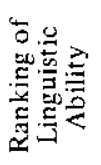 & Description of Linguistic Output \\
\hline $\mathrm{LI}_{1}$ & $4 ; 3$ & 3 & 3 & 4 & $\begin{array}{l}\text { Multiple phonologic and Synt actic } \\
\text { deviations. Vocabulary fair. }\end{array}$ \\
\hline N1 & $4 \cdot 2$ & 2 & 2 & 2 & $\begin{array}{l}\text { Normal syntax and phonology } \\
\text { with developmental errors. } \\
\text { vocabulary fair. }\end{array}$ \\
\hline $\mathrm{LI}_{2}$ & $4 ; 7$ & 2 & 3 & 3 & $\begin{array}{l}\text { Syntactic and mild phonological } \\
\text { deviations. Vocabulary fair. }\end{array}$ \\
\hline $\mathrm{N}_{2}$ & $4 ; 7$ & 4 & 4 & 1 & $\begin{array}{l}\text { Sophisticated mature syntax and } \\
\text { phonology. /S/Articulation error. } \\
\text { Vocabulary good. }\end{array}$ \\
\hline
\end{tabular}

TABLE 1: lntersubject Differences

\section{TESTS USED IN THE STUDY}

A selection pretest was first administered (for purposes of subject selection) followed by the semantic feature manipulation tests.

For purposes of clarification the tests administered will be discussed in terms of the rationale for their use, and a description of the test materials.

\section{Pretest}

For selection purposes a pretest was conducted to ensure that all subjects could categorize conceptually and to establish to which commands they responded best, in order to select the command most effective for subsequent testing. Use was made of several three-dimensional objects exemplifying the conceptual categories of "dolls", "animals" and "fruit and vegetables".

Semantic Feature Manipulation Tests.

Two sets of material manipulating semant ic markers, were const ructed in order to assess what features constitute the child's verbal concept, what "' referent types he has present in his vocabulary, what contrasts he draws between referents, and how the semantic features selected relate to his experience.

Two superordinate concepts. were utilized for the purposes of this test "furniture" and "containers". These superordinates were selected as the child has variable contact with these in his environment:. Through discussion with the parents of subjects, it seems that "furniture" is subject to active teaching by parents, whereas "containers" seem to be more passively taught. It was 
felt that there might consequently be a difference in the manner in which the child would form the concepts underlying these two superoidinates. It was also felt that the less familiar class might yield interesting results which could possibly differentiate between language impaired and normal children in the way they learn passively defined concepts.

In the adult lexicon both superordinates fall under the following hierarelic feature matrix.

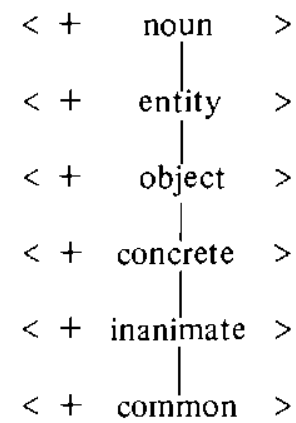

We may not, however, assume that this is so in the child's lexicon.

Rather, word association studies with children have led to confusion about what features might be present. Word-association studies cited by Anglin ${ }^{1}$ show that young children tend to associate stimulus words with words of otl:er form-classes, e.g. "ball" elicits the response "throw". However, the present writer feels that this heterogeneity probably results from the functional use of the words being grouped together in frequently used contexts. It is consequently felt that the conclusion drawn by Anglin, ' namely that children do not have distinct form classes, is an invalid one.

Rather, in observing normal four-year-olds, we can assume that, as they make use of nouns interchangeably in similar semantic relations, nouns are functionally and syntactically equivalent for them. For example, because "cat" and "dog" are interchangeable in the same relations they can be assumed to belong to the same form-class (as drawn from Bloom's ${ }^{4}$ conclusions).

Thus it is felt that investigation into one form-class is appropriate for this age group, and removes confounding variables introduced by word-association tasks.

The form-class of nouns has been selected in this study, as nouns' referents are easily represented in a manner which cannot be easily misinterpreted by the child - by models or pictures. Models, then, are amenable to the manipulation of those physical features which are regarded as representative of possible semantic markers, and it is through the use of such models that it is proposed one can come to understand the concepts of referents which the child has labelled. ${ }^{15}$ 
As categorization into subordinate classes requires the abstraction of common criterial features, a categorization task can be used for investigating classmembership criteria - that is, what features constitute the concept.For the purposes of deducing the criterial semantic markers, a set of semantic markers was manipulated in terms of all possible interrelationships. The features common to all objects categorized similarly, are then the criterial features for that class.

Rosch 22 shows that each concept has focal and peripheral exemplars, due to its internal structure. Focal items are those which most accurately incorporate the ideal features of the concept. These items are not ambiguous and can be interpreted only as exemplars of the original concept. Peripheral items do not incorporate all the critical features of the concept and because of their insufficient definition can be incorporated into other concepts (being on the periphery between them). They are in this sense ambiguous. It was decided to determine these as it was felt that focal items would demonstrate those semantic features most typical of the class.

The semantic features manipulated were perceptually present, three-dimensional physical features of the objects, e.g. back and seat. The use of visual stimuli and primarily nonverbal responses was motivated by findings that children demonstrated improved performance on such tasks, in contrast to those where stimuli and responses were verbal. ${ }^{1,5}$

Description of semantic feature manipulation test materials:

The features of eight types of furniture items present in the adult vocabulary were systematically manipulated in 127 wooden models. The furniture items selected for feature manipulation were: bed, table, desk, dressing-table, stool, chair, bench and couch.

Containers representing eight items focal in adult language were selected: cup, mug, glass, jug, jar, bowl, bottle and vase. Only certain features which ran almost throughout all the types were manipulated e.g. lid. In all 47 real-size objects were used, because, in contrast to the furniture, models are difficult to construct, and items of real size are portable.

\section{PROCEDURE}

On all tests subjects were tested individually by the experimenter in quiet, familiar surroundings. The pretest was administered in their homes in order for experimenter to establish rapport with the subject and to eliminate unnecessary tension which affects test responses. ${ }^{7}$ The remaining tests were carried out in an isolated room at the children's nursery schools, except in the case of $\mathrm{LI}_{2}$, who was tested at home due to unavoidable circumstances. In all test enviroments an attempt was made to decrease extraneous distracting stimuli to ensure maximal attention being directed to test materials. Each testing session was broken by frequent short rest intervals (about three minutes) whenever subjects showed evidence of restlessness or fatigue, due to the limited concentration span of the four-year-old. 
Figure 1 Systematic manipulation of semantic features shown on examples of the "bed" series

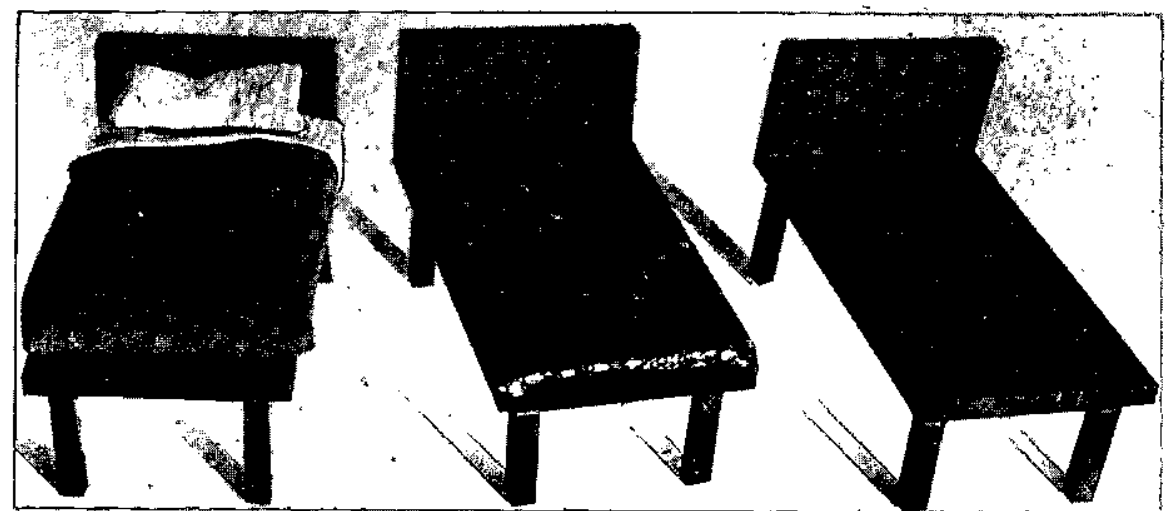

Fig. $1 a$.

$\left[\begin{array}{lr}<+4 \text { legs. } \\ <+ \text { top } \\ <+ \text { headboard }> \\ <+ \text { bedding } & > \\ <+ \text { mattress } & >\end{array}\right]$
Fig. $I b$.

$\left|\begin{array}{lr}<+4 \text { legs } & > \\ <+ \text { top } & > \\ <+ \text { headboard }> \\ - \text { bedding } & > \\ <+ \text { mattress } & >\end{array}\right|$
Fig. $1 c$.

$\left[\begin{array}{lr}<+4 \text { legs } & > \\ <+ \text { top } & >+ \text { headboard }> \\ <- \text { bedding } & > \\ <- \text { mattress } & >\end{array}\right]$

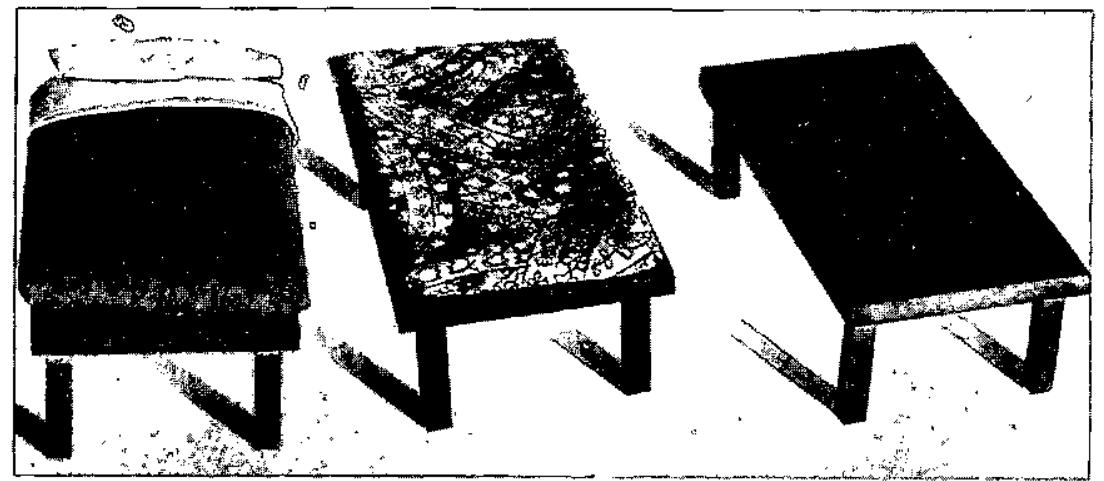

Fig. $1 d$.

$\left[\begin{array}{lr}<+4 \text { legs } \\ <+ \text { top } \\ <- \text { headboard }> \\ <+ \text { bedding } & > \\ <+ \text { mattress } & >\end{array}\right]$
Fig. Ie.

$\left[\begin{array}{lr}<+4 \text { legs . } \\ <+ \text { top } \\ <- \text { headboard }> \\ <- \text { bedding } & > \\ <+ \text { mattress } & >\end{array}\right]$
Fig. $1 f$.

$\left[\begin{array}{lr}<+4 \text { legs } & > \\ <+ \text { top r } & > \\ <- \text { headboard }> \\ <- \text { bedding } & > \\ <- \text { mattress } & >\end{array}\right]$ 
Feature manipulation tests

Before the feature manipulation tests could bc administered, it was necessary to ensure that subjects could categorize in terms of the superordinates. Four, two-dimensional photographs of each superordinate were required to be sorted into two groups (i.e. containers and furniture).

The following tests were then performed:

1. Free categorization: Subjects spontaneously sorted firstly the furniture and then the containers, int o classes. It was felt that such sorting would tap the superordinates relevant to the child.

2. Forced categorization: Subjects were required to categorize objects into classes labelled by the experimenter, to ascertain whether these concepts were present in the child's lexicon.

3. Subjects were then required to select focal versus peripheral menbers of the forced catcgories.

Method of recording and analysing responses

All responses were recorded by the experimenter in written form. The results were then analysed by examining the feature matrices of each item in the sub. ject's grouping, and abstracting out the features common to the exemplars of the category.

\section{RESUI.TS $\triangle$ ND DISCUSSION}

In dealing with the results an attempt will be made to analyse and discuss the responses of the subjects qualitatively on each test. This will be followed by a general discussion of the important trends emerging from this study.

\section{PR I'IISS'T'}

All subjects were able to supersede perceptual cațegorization and categorized according to named superordinates, although each subject used different methods of categorization.

I.I immediately attempted categorical sorting, grouping dolls together. He then sorted more primitively according to the common feature of colour , ' (i.e. perceptually). Although behaving inappropriately, he was unable to alter his mode of response until the experimenter prompted this by suggesting an alternative. He then sorted cntirely conceptually, ignoring perceptual features. Both subordinates and superordinates were labelled, although the category "fruit and vegetables" was namely functionally - 'we eat them'

$\mathrm{I}_{2} \mathrm{I}_{2}$ demonstrated a cat egorical attitude, sorting according to superord inates. He scemed also to use complexive thought, as, after two yellow fruit items were grouped together, he began sorting perceptually, according to colour. When prompted, he again commenced conceptual categorization, including 
colour-categorization within classes. Subordinates and superordinates were labelled.

$\mathrm{N}_{1}$ sorted concretely (i.e. perceptually) according to colour at first, but when requested to change his mode of response, categorized conceptually. He was then able to name subordinates and labelled superordinates "dolls", "fruits" and "animals".

$\mathrm{N}_{2}$ first evidenced concrete sorting, grouping into sets of identical objects. However, responses immediately became conceptual when instructions were modified from sorting "things that are the same to things that are a little bit the same". Superordinates were termed "dolls", "fruit we eat" and "animals."

All subjects were selected for participation in feature manipulation tests on the basis of their ability to sort conceptually, especially with appropriate commands.

\section{FEATURE MANIPULATION TESTS}

As the results on these tests are too lengthy to present in full in a report of this nature, pertinent examples of typical responses will be presented in the frame-work of an analysis and discussion of the results.

Relationship between parent word-referent model and child's responses

An examination of the data reveals that there is a close correlation between the child's knowledge of word-referent relationships and the amount of contact he has had with the word-referent relationship from his mother's speech. Therefore, in those word-referent relationships very frequently encountered by the child, the feature specification was identical to that of the mother. Less known relationships were seen to be less-adequately defined by the child (see Figure 2). More actively taught relationships (i.e. "furniture") were apparently better known.

\section{Free categorization}

In examining the results it is evident that free categorization generally led to the abstraction of objects into broad, ill-defined categories. These categories were labelled and their feature-specification incorporated few semantic markers. For example, the category "chair" (incorporating the features $<+$ back $>$ $<+$ seat $>$ ) was seen to contrast with "table" (which incorporated $<+$ top $>$ $<+$ legs $>$ ). In terms of the evidence that these categories were able to be subdivided into more specific categories, it seems that subjects spontaneously categorized into their superordinates. Forced categorization, therefore, led to subjects sub-dividing the superordinates. The superordinate categories thus evidenced were more specific and incorporated a greater number of semantic markers including those general markers specifying the superordinate. For example, $\mathrm{LI}_{1}$ was able to sub-divide the superordinate "table" in the following manner - 


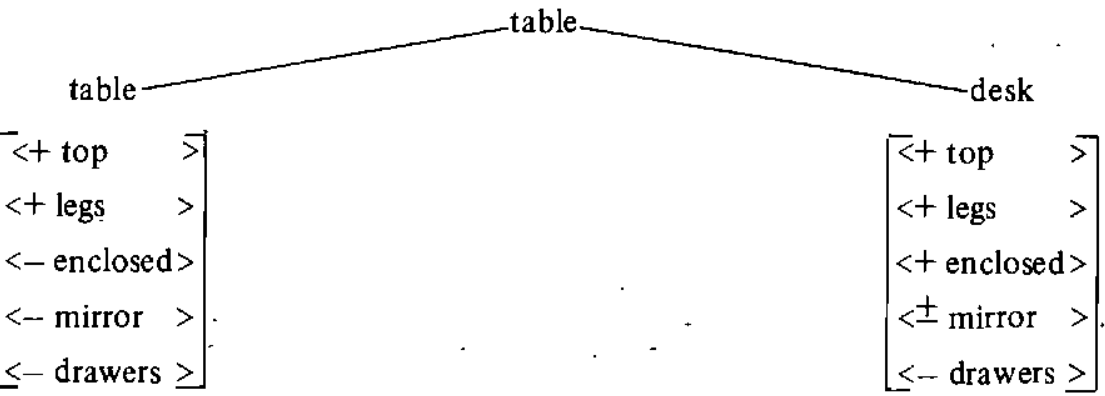

Forced categorization

The following generalizations may be drawn from the results:

The child's method of categorization correlated strongly with his contact with word-referent relationships. Thus the subjects showed greater ease in naming and categorizing conceptually with familliar word-referent relationships. This was seen in contrasting between "furniture and "containers" as well as within these general categories.

From the forced categorization of objects, the following types of word-referent relationships emerged. ( See Figure 2).

Figure 2. Word-Referent Relationships found in the study

Known Referent-Label

Relationships

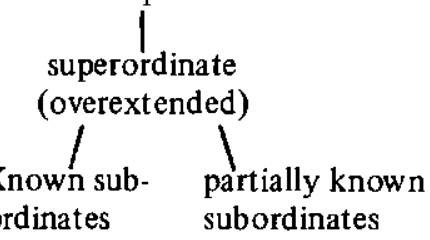

(All

subjects)
Unknown Referent- Label Relationships

$\begin{array}{ll}\text { Categorized } & \begin{array}{l}\text { Categorized } \\ \text { referents }\end{array} \\ \text { referents } & \text { unat tached } \\ \text { attached } & \text { to meaningless } \\ \text { randomly to } & \text { label } \\ \text { meaningless } & \text { labels }\end{array}$

The strategies of abstraction were closely affected by the type of word-ref-; erent relationship applicable. As can be seen from the above figure, all subjects had the ability to categorize conceptually with the meaningful stimuli. When they were familiar with the label applicable to the stimuli they sorted according to the correct superordinate. They were also able to show exemplars of familiar superordinates when asked to do so. However, with less familiar or less meaningful word-referent relationships (i.e. unknown referent-label relationships) the subjects were faced with the task of ascribing meaning to the unfamiliar objects, and this was achieved by the use of certain general strategies: 
The unfamiliar objects were perceptually sorted or else sorted together into undifferentiated heaps. Sometimes the language-impaired subjects labelled perceptually grouped items in terms of an arbitrary unfamiliar label - for example "stool" was randomly used to name a class of unfamiliar objects. Normal children would not do so if the name was unfamiliar.

Where the label was familiar to the subjects but only partially meaningful in terms of its attachment to referents it was apparent that all the subjects were uncertain of the referents, as in the cases of "dressing table" and "desk" (See Figure 3). In this event it seemed that an attempt was made by subjects to hypothesize sets of abstracted features for the labels, and all subjects became perceputally bound to the present stimuli. They seemed to attempt to abstract out two sets of features, one set applicable to each label, each set of features being mutually exclusive. Thus each subject reached a different feature specification, although all were seen to work from concrete comparisons See Figure 3. $\mathrm{N}_{2}$, however, was the only subject to achieve totally exclusive feature specifications for these two classes even though his deductions led to categorizations different from those made by the adult.

Figure 3. Feature specification deduced from subjects' differentiation of the partially known labels "dressing table" and "desk".

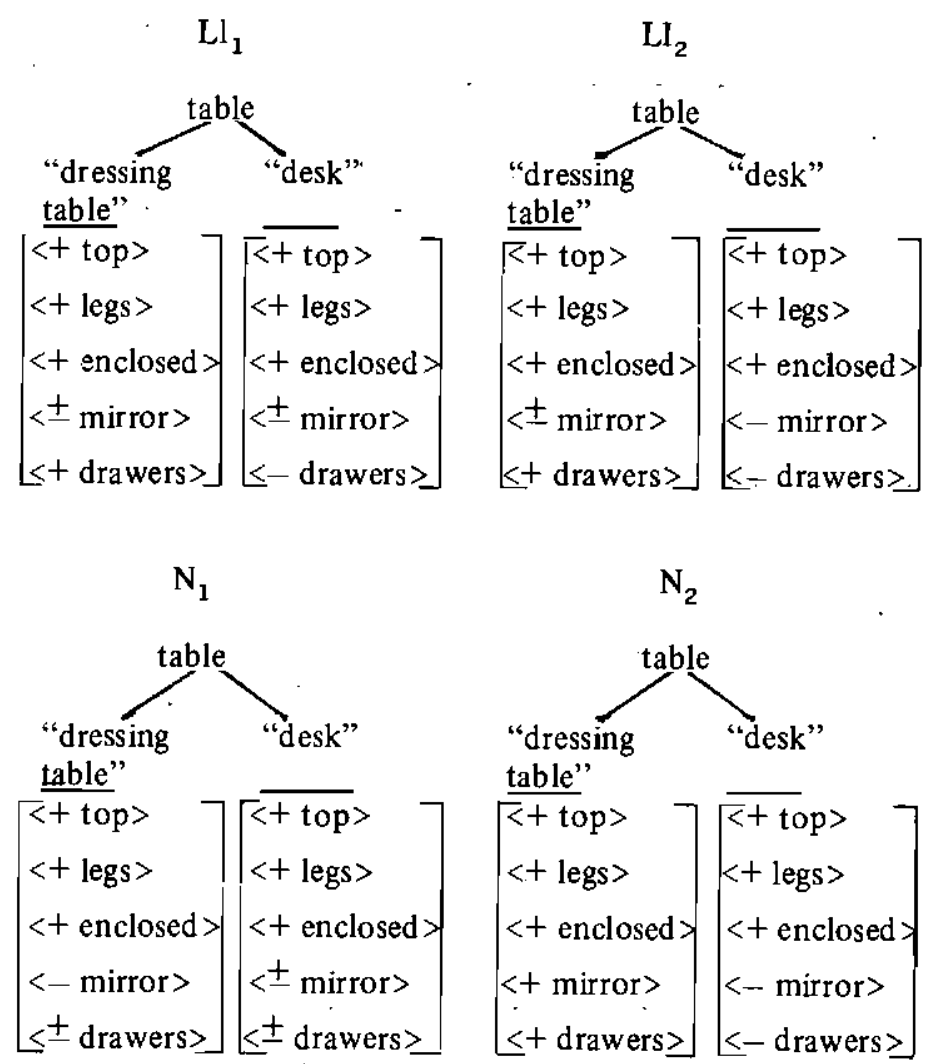


Conversely, where a referent seemed appropriate to two sets of objects, sub. jects $\mathrm{LI}_{1}, \mathrm{LI}_{2}$, and $\mathrm{N}_{1}$ grouped these items perceptually. These items were, therefore, evaluated in terms of which item they closest resembled, and were named similarly. For example, in being presented with the object with four legs, and a padded top surface, these subjects compared this to certain items previously categorized as beds, because of their headboards. In a manner typical of complex thought, the feature of padding (or $<+$ mattress $>$ ) was abstracted, and the unlabelled item termed "bed". However, $\mathrm{N}_{2}$ did not depend on perceptual stimulus-bound comparisons. Rather he labelled this item a "table" drawing on his past experience, where the features of the present item conformed with the features of the schema for "table".

While no conclusion about semantic acquisition may be drawn from the data on familiar subordinates, unfamiliar subordinates furnish interesting in forma. tion. It is these subordinates which are in the process of developing and thus it is possible to discuss whether the process of development in the child with already established language, is in agreement with a semantic feature acquisition hypothesis. In order to assess this, it is necessary to examine the validity of the principle of overextension, as well as the direction of semantic growth on those developing word-referent relationships.

For the purposes of this discussion, a developing word-referent relationship will be defined as a label whose semantic feature specification is incomplete in terms of the adult model, although approximating this e.g. with "desk" and "dressing table". From examination of the data two types of developing relationships are found: (a) Where the adult model implies an incomplete feature specification (e.g. with $\mathrm{LI}_{2}$ the model word "cup" used by the mother implies incomplete specification as it refers to all drinking utensils - see Table IIB); and (b) Where the adult model incorporates all differentiating features (e.g. the parents of all subjects adequately contrast "desk" with "dressing table" and thus these model labels can be assumed to incorporate all semantic features).

The several examples of such relationships seen in the data seem to demonstrate that all subjects follow a common trend.

As an instance of type (a) it is seen that in all subjects "bench" and "couch" were not contrasted either in the adult model or the child's vocabulary item. The feature specification of these was uniform amongst all children, but the label attached conformed to the relevant adult's model. The feature specification was

$$
\left[\begin{array}{lr}
<+ \text { back } & > \\
<+ \text { seat } & > \\
<+2 \text { people }> \\
<+ \text { legs }
\end{array}\right] .
$$

which excluded the feature differentiating between the two labels ("bench" and "couch") (i.e. <+ upholstery > or <- upholstery >). Thus both adult model and child word can be termed overextended, and not superordinate, 


\begin{tabular}{|c|c|c|c|c|c|c|c|c|}
\hline$z^{N}$ & 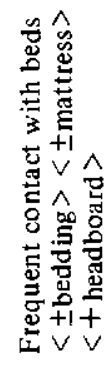 & 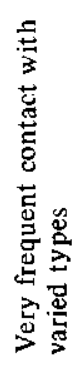 & 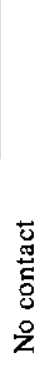 & 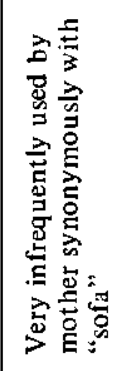 & 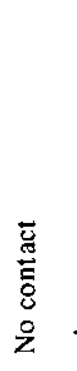 & 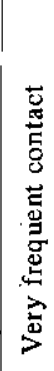 & 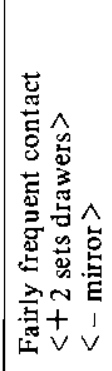 & 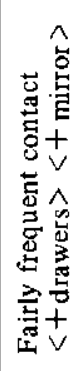 \\
\hline $\mathbf{z}^{-1}$ & 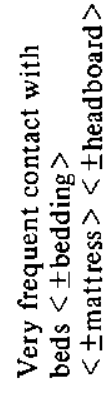 & 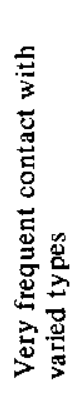 & 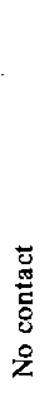 & 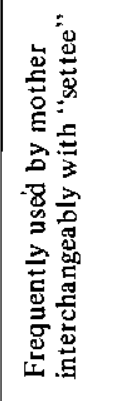 & 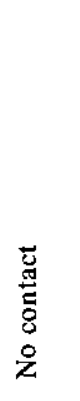 & 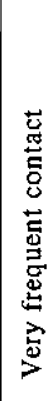 & 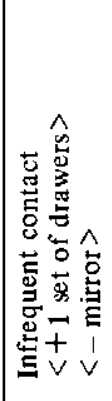 & 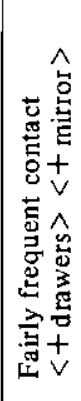 \\
\hline$\Xi^{N}$ & 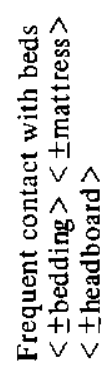 & 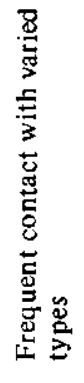 & 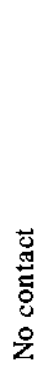 & 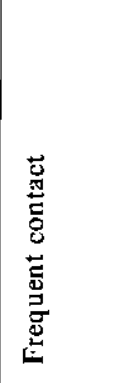 & 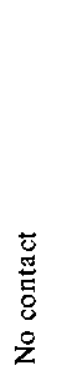 & 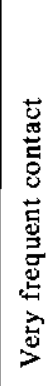 & 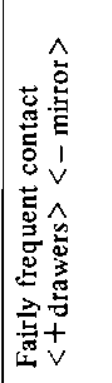 & 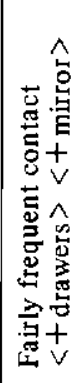 \\
\hline$\vec{\Xi}$ & 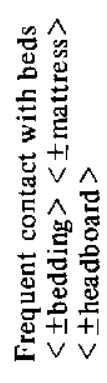 & 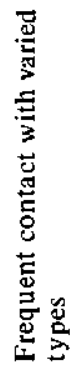 & & & 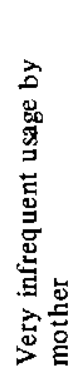 & 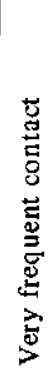 & 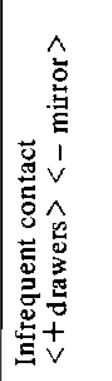 & 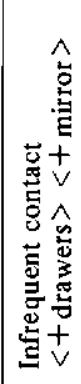 \\
\hline & 䓌 & 莺 & $\begin{array}{l}\text { 离 } \\
\text { 怘 } \\
\text { }\end{array}$ & $\begin{array}{l}\text { 를 } \\
\text { ठ }\end{array}$ & $\begin{array}{l}\overline{8} \\
\dot{s}\end{array}$ & 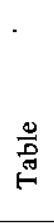 & 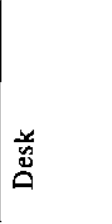 & 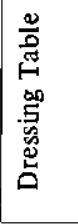 \\
\hline
\end{tabular}




\begin{tabular}{|c|c|c|c|c|c|c|c|c|}
\hline$z^{N}$ & 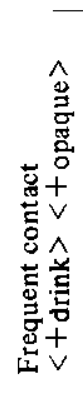 & 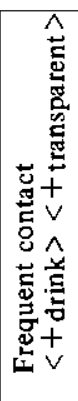 & 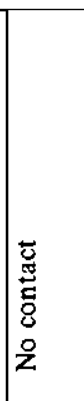 & 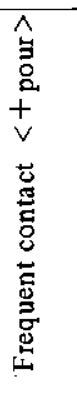 & 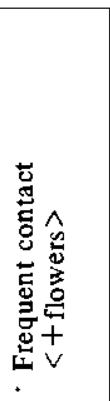 & 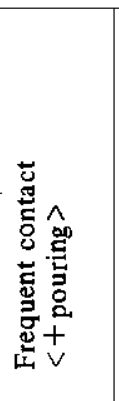 & 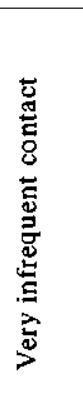 & 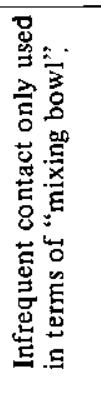 \\
\hline $\mathbf{z}^{-1}$ & 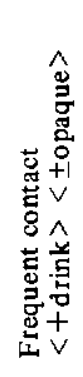 & 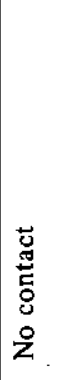 & 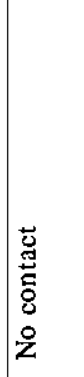 & 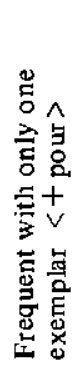 & 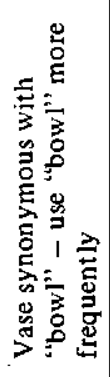 & 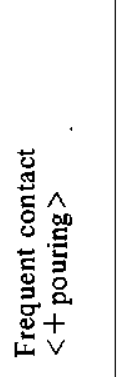 & 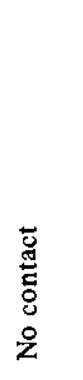 & 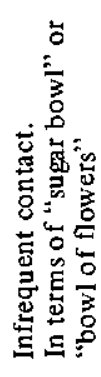 \\
\hline$\Xi$ & 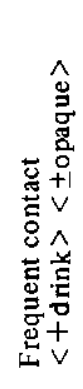 & 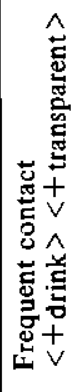 & 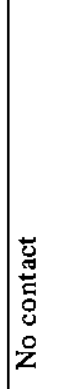 & 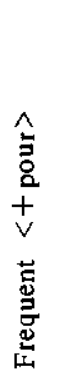 & 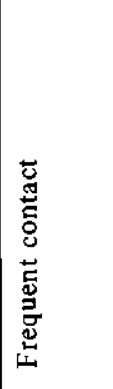 & 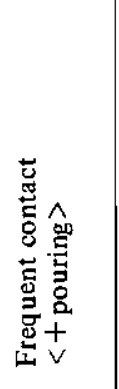 & 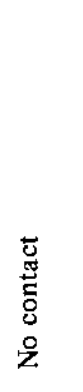 & 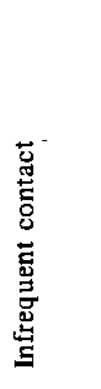 \\
\hline$\Xi$ & 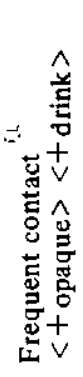 & 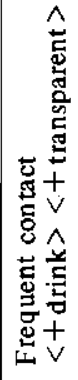 & 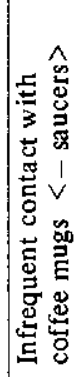 & 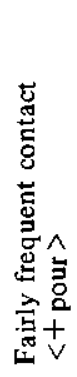 & 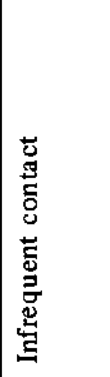 & 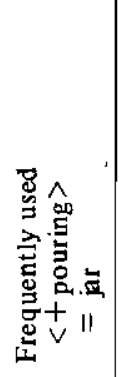 & 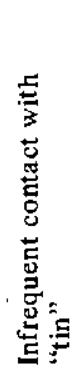 & 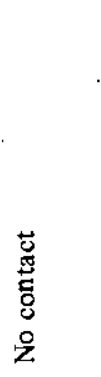 \\
\hline & 己े & \begin{tabular}{l}
$\mathscr{2}$ \\
\multirow{3}{*}{}
\end{tabular} & $\frac{a}{2}$ & $\stackrel{m}{g}$ & 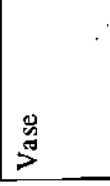 & $\begin{array}{l}\stackrel{0}{\Xi} \\
\vdots \\
0\end{array}$ & 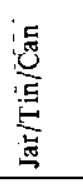 & $\overrightarrow{\bar{O}}$ \\
\hline
\end{tabular}


because the real superordinate would make use of a different label (e.g. perhaps "double chairs" as used by $\mathrm{N}_{2}$, or "furniture.")

In terms of type (b) the explanations of the evolution of the terms "desk" and "dressing table" already proposed, seems also to support the semantic feature acquisition theory, as in all subjects an at tempt was made to elaborate a detailed feature specification.

ln both types of evolving word-referent relationships the growth seems, therefore, to proceed hierarchially in a downward direction - i.e. from generalized overextended terms to more differentiated, specific word-referent relationships, with nevertheless incomplete feature matrices.

Language-impaired and normal subjects were not able to be differentiated on these tests, except in terms of the unknown referent-label relationships as seen in Figure 2.

Focal versus peripheral categorization

Known word referent-relationships:

In all subjects it was seen that focal and peripheral exemplars included certain features which seemed to be essential to the exemplar being included in the class. These features were deduced by the experimenter to be the critical features of the class. These features, present in the focal exemplar but absent in the peripheral, were necessary for the object to be a realistic examplar of a class. However, even if these features were absent the item was categorized as a peripheral exemplar of the class if the critical features were present.

For example all subjects contrasted focal and peripheral chairs in the following way:

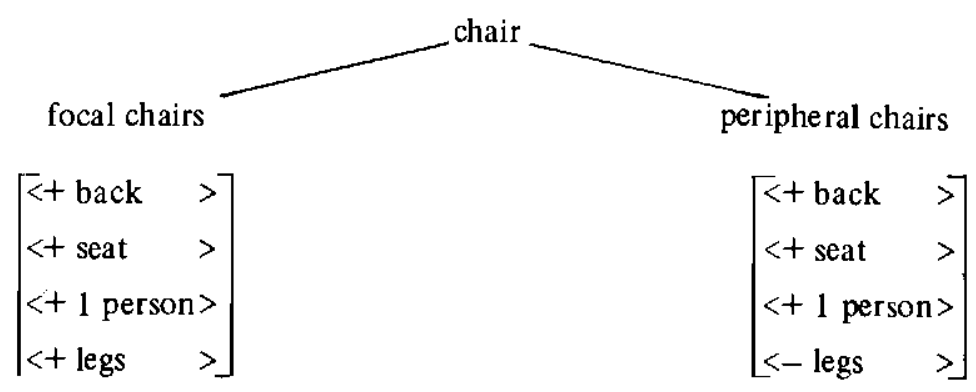

Unknown word-reférent relationships:

All subjects were unable to differentiate focal and peripheral exemplars on any of these.

\section{GENERAL DISCUSSION}

The general discussion will be concerned with the implications and limitations of the present study.

Investigation is indicated into later semantic feature acquisition, in order to determine whether all subordinate terms (with completed feature specifications) must be acquired, before the child becomes able to abstract out super- 
ordinate features and concept like <+ animate $>$ and $<-$ animate $>$ which are established later in semantic development. ${ }^{24}$

Language-impaired subjects were seen to cope well when the word-referent relationships were familiar through frequent usage in their environments. Therapeutically, this implies that vocabulary can be best learned when the lexical item is frequently paired with varying exemplars of the same category, and that at tention should be drawn to the constant elements present in all the examples - i.e. the critical semantic markers.

The limitations of this st udy lie mainly in its use of a small sample, which prevents the generalization of conclusions. Furthermore, only a small aspect of semantic theory was investigated. Such limitations imply the necessity for further research.

The subjectivity of a qualitative analysis of responses, as well as the tediousness of detailed semantic marker manipulation testing, provide major criticisms of this study

\section{CONCLUSION}

In conclusion, tasks of semantic feature manipulation reveal that there is reality for a semant ic feature acquistion model, where the child draws firstly on predefined concepts from experience, and then from present perceptual data to attribute word-meanings to stimuli.

Words receiving conscious and active teaching are acquired with more definition than those learned less actively, though no differences seemed to exist between language-impaired and normal children on this level.

\section{REFERENCES}

1. Anglin, J.M. (1970): The growth of Word Meaning. Cambridge, Massachusetts: M.I.T. Press.

2. Berry, M.F. (1969): Language Disorders of Children: The Bases and Diagnoses. New York: Appleton-Century-Crofts.

3. Bierwisch, M. (1970): Semantics. Ch.1 in J. Lyons (Ed.), New Horizons in Linguistics. Penguin Books.

4. Bloom, L. (1973): One Word at a Time. The Hague: Mouton.

5. Brown, R. (1956): Language and Categories. Appendix in Bruner, J.S., Goodnow, J.J., and Austin, G.A. A Study of Thinking. New York: John Wiley and Sons, Inc.

6. Brown, R. (1970): The Child's Grammar from I to III. Ch. 6 in R. Brown. Psycholinguistics: Selected Papers. New York: The Free Press.

7. Bruner, J.S. Goodnow, J.J., and Austin, G.A. (1956): A study of Thinking. New York: John Wiley and Sons inc.

8. Bruner, J.S., Olver, R.R., and Greenfield, P.M. (1966): Studies in Cognitive Growth. New York: John Wiley and Sons Inc.

9. Carrol, J.B. (1964): Language and Thought. Englewood Cliffs, New Jersey: Prentice-Hall Inc. 
10. Clark, E.V. (1973): What's in a Word? On the Child's Acquisition of Semantics in His First Language. In T.E. Moore (Ed.) Cognitive Development and the Acquisition of Language. New York and London: Academic Press, Inc.

11. Hoffman, H.N. (1955): A study in an Aspect of Concept Formation with Subnormal, Average and Superior Adolescents. Genetic Psychology Monographs, 52,193-239.

12. Johnson, D.M. (1972): A Systematic Introduction to the Psychology of Thinking. New York: Harper and Row.

13. Johnson, W., Darley, F.L., and Spriestersbach, D.C. (1963): Diagnostic Methods in Speech Pathology. New York: Harper and Row.

14. Katz, J.J. (1972): Semantic Theory. New York: Harper and Row.

15. Lanham, L.W. (1974): Personal Communication.

16. McNeil, D. (1970): The Acquisition of Language: The Study of Developmental Psycholinguistics. New York: Harper and Row.

17. Menyuk, P. (1971): The Acquisition and Development of Language. Englewood Cliffs, New Jersey: Prentice-Hall, Inc.

18. Narun, L. (1973): Speech Pathology III, Lecture Notes, University of the Wit watersrand, Johannesburg.

19. Olson, D.R. (1970): Language and Thought: Aspects of a Cognitive View of Semantics. Psychological Review, 77, (4) 257-273.

20. Olson, D.R. (1970): Cognitive Development: The Child's Acquisitional Diagonality. New York and London: Academic Press.

21. Rees, N.S. (1973): Auditory Processing Factors in Language Disorders: The View from Procrustes' Bed. J. Speech Hearing Disorders, 38(3), 304315.

22. Rosch, E.H. (1973): On the Internal Structure of Perceptual and Semantic Categories. In T.E. Moore (Ed.) Cognitive Development and the Acquisition of Language. New York and London: Academic Press, Inc.

23. Rosenstein, J. (1963): Concept Development and Language Instruction. Exceptional Children, 30, 337-343.

24. Schaeffer, B., Lewis A.E., and Van Decar, A. (1971): The Growth of Children's Semantic Memory: Semantic Elements. J. Experimental Child Psychology, 11, 296-309.

25. Strauss, A.A.; and Lentinen, L.E. (1950): Psychopathology and Education of the Brain Injured Child. New York: Grune and Stratton.

26. Vygotsky, L.S. (1962): Thought and Language. New York and London: M.I.T. Press. 


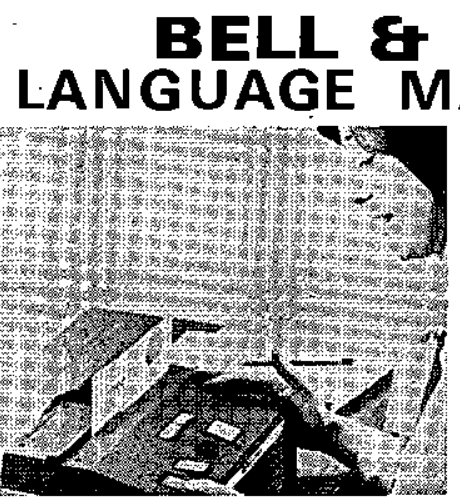

Teacher records the master track on a mains-powered Language Master.

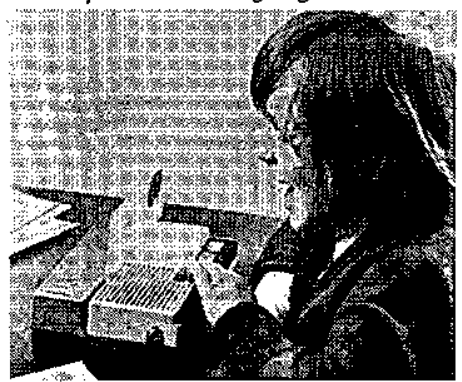

Pupil makes his own recording, in response to what the teacher has said.

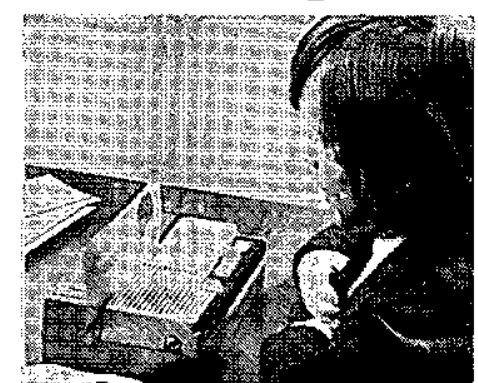

On a classroom 1727, pupil listens to the teacher's recorded voice.

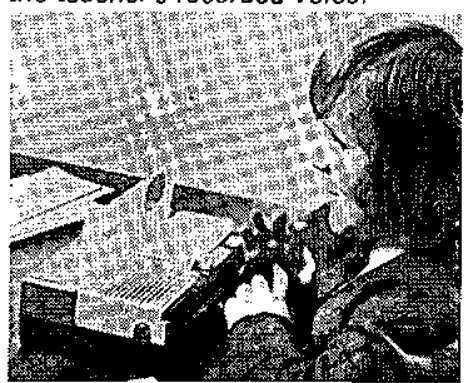

Pupil listens to his own recording, then compares it with the teacher's. If. he is not satisfied, he can rerecord (re-recording automatical/y erases the rrevious pupil recording. but leaves the teacher's recording unimpaired).

\section{THE NFFNITEYY PATIENT LANEUAGE MASTER}

Reading: In learning to read, listening is a key factor. By its unique combination of sight and sound, the Language Master System enables the child to look at a whole word or a phonic element within a word and at the same time hear the correct pronunciation on the teacher's track.

Speech Therapy: Because of the infinitely patient, individual attention it provides, the Language Master System is particularly useful in teaching both reading and speech to children or adults who are handicapped in some way (e.g. by aphasia, speech impediments, partial deafness).

For further information contact the Language Master consultant at Gallo-Fox in Johannesburg. P.O. Box 31884, Braamfontein 2017. Tel.: 28-6152. 